\title{
Study on Conservation Threats on African elephant (Loxodonta africana, Blumenbach, 1797) in Babile Elephant Sanctuary, Eastern Ethiopia
}

\author{
Taye Lemma Geleta ${ }^{1}$ and Girma Mengesha ${ }^{2}$ \\ ${ }^{1}$ College of Natural and Computational Sciences Centre for Environmental Sciences, \\ Addis Ababa University, Ethiopia \\ ${ }^{2}$ Wondo Genet College of Forestry and Natural Resources, Hawassa University, \\ Addis Zoo Park, Addis Ababa, Ethiopia
}

\begin{abstract}
The focus of this paper is to study the conservation threats on African elephants in Babile Elephant Sanctuary, Eastern Ethiopia. A simple random sampling method was used to gather data from sampled households. Total of 138 households were selected for interview nearby the study area, and qualitative survey was collected. Focus group discussion and site observations were carried out. According to the result showed, all respondents (100\%) were perceived that the population explosion around the sanctuary was increasing for encroaching the land. Following human population, settlement (89.13\%), human-elephant conflict (87.7\%), and agricultural expansion (87\%) through deforestation (84.7\%) were the major threats that faced the sanctuary. The result also revealed that livestock grazing, charcoal production, poaching, less community participation, ineffective law enforcement, illegal (uncontrolled) fire, excavation of sands, and fuelwood collection were other discerned threats. Besides, less than (45\%) of them were believed as hunting (i.e., other than elephants), lack of management capacity, ineffective stakeholders \& partners involvement were brought less effect on present elephant conservation when related with other threats. However, only $22 \%$ of respondents were agreed with the existing management system. This might showed why the increased number and types of threats were observed in the sanctuary. Overall, this study disclosed the existence of conservation threats. Based on research results, the following inference is drawn: awareness creation for local communities and other stakeholders along with benefit-sharing for nearby communities around the sanctuary is important to lower the threats then conserve and protect elephant habitat and the values of the sanctuary. Moreover, strengthening the capacity of management and enforcing laws can minimize the intimidation and enhance opportunities.
\end{abstract}

Keywords: African elephant, Babile Elephant Sanctuary, Conservation threats, Eastern Ethiopia, Local communities.

\section{INTRODUCTION}

\subsection{Background and Justification}

In Ethiopia, there are three sub-species of the African elephants L. africana that are found in the country (i.e. L. a. oxyotis, L. a. knochenhaueri, and L. a. orleansi) (Yalden et al., 1986). Presently, the sub-species L. a. orleansi is found in the lowlands of the semi-arid region of eastern Ethiopia (i.e., in the Babile Elephant Sanctuary-BES) (Yalden et al., 1986). Elephants in Ethiopia are among the 37 mammal species that are threatened by extinction (Yirmed Demeke et al., 2006). Since the 1980s, Ethiopia has lost about $90 \%$ of its elephant population (Yirmed Demeke et al., 2006). The decline of the African elephant (Loxodonta africana, Blumenbach, 1797) in Ethiopia in general and specifically in the study area of BES can be linked with killing elephants (i.e., poaching) to satisfy the demand for ivory (Sintayehu et al., 2016), and Human-Elephant Conflict (HEC) for the use of land, and the rapid growth of human populations changing the land-use patterns (Anteneh Belayneh, 2006; Zelalem Wodu, 2007) and continuous decline in the extent and quality of elephant habitats all over its range (SDPASE/EWCA, 2015) and alteration of natural habitats through cultivation, livestock grazing, deforestation for fuelwood and construction, uncontrolled bush fires for charcoal production and investment for bio-fuel production, construction of road and human settlement activities that affect the habitats of African elephants are the major threats to Elephant Range State (ERS), particularly in BES (Yirmed Demeke, 2003; Anteneh Belayneh ,2006; and Zelalem Wodu, 2007; Sintayehu et al., 2016). Besides, lack of financial and human resources, commitment, law enforcement, and inaccessibility and remoteness from the main road are also other encounter to conserve elephants. Therefore, the above-mentioned factors have severely affected elephant populations in the country in general and specifically to BES. Due to this, nationally elephants are considered critically endangered species (Blanc, 2008). 
Corresponding author:-Taye Lemma Geleta, EWCA, P.O.Box (386), Addis Ababa, Ethiopia; Email:taye.lemma@ambou.edu.et So, information on threats in the sanctuary is vital to conserve and manage this vulnerable species. Since this was scarcely or not yet documented, this study was conducted. Hence, understanding the causes of the threats for peaceful co-existence between surrounding communities is very important to conserve in particular elephants and in general other wildlife resources which were inside and/or outside the sanctuary areas. Additionally, the study generates up-to-date information on drivers (e.g., anthropogenic factors such as deforestation, invading species, human-elephant conflict) leading to the extinction of the elephant $L$. $a$. Orleansi species. But, relatively few studies were available with regards to threats (e.g., Human-Wildlife Conflict/Human-Elephant Conflict) of African elephants (Sintayehu Workeneh and Uttama Ready, 2014) in the sanctuary. Thus, this study was important to investigate up-to-date interactions with humans, to promote conservationists to design a suitable plan to worsen the threats.

\section{MATERIALS AND METHODS}

\subsection{Description of the study area}

Babile Elephant Sanctuary (BES) was established in 1970, with area coverage of about $6,982 \mathrm{~km}^{2}$. It is located at about $560 \mathrm{~km}$ distant from the capital city of Addis Ababa in the eastern part of the country; between Oromia (Eastern Hararge high mountainGara- Muleta to the west) and Ethio-Somali (Ogaden Desert to the southeast) regional states (Yirmed Demeke, 2008). Geographical position is within latitudes of $08^{\circ} 22^{\prime} 30^{\prime \prime}-09^{\circ} 00^{\prime} 30^{\prime \prime} \mathrm{N}$ and longitudes of $42^{\circ} 01^{\prime} 10^{\prime \prime}-43^{\circ} 05^{\prime} 50$ "E (Figure 1).

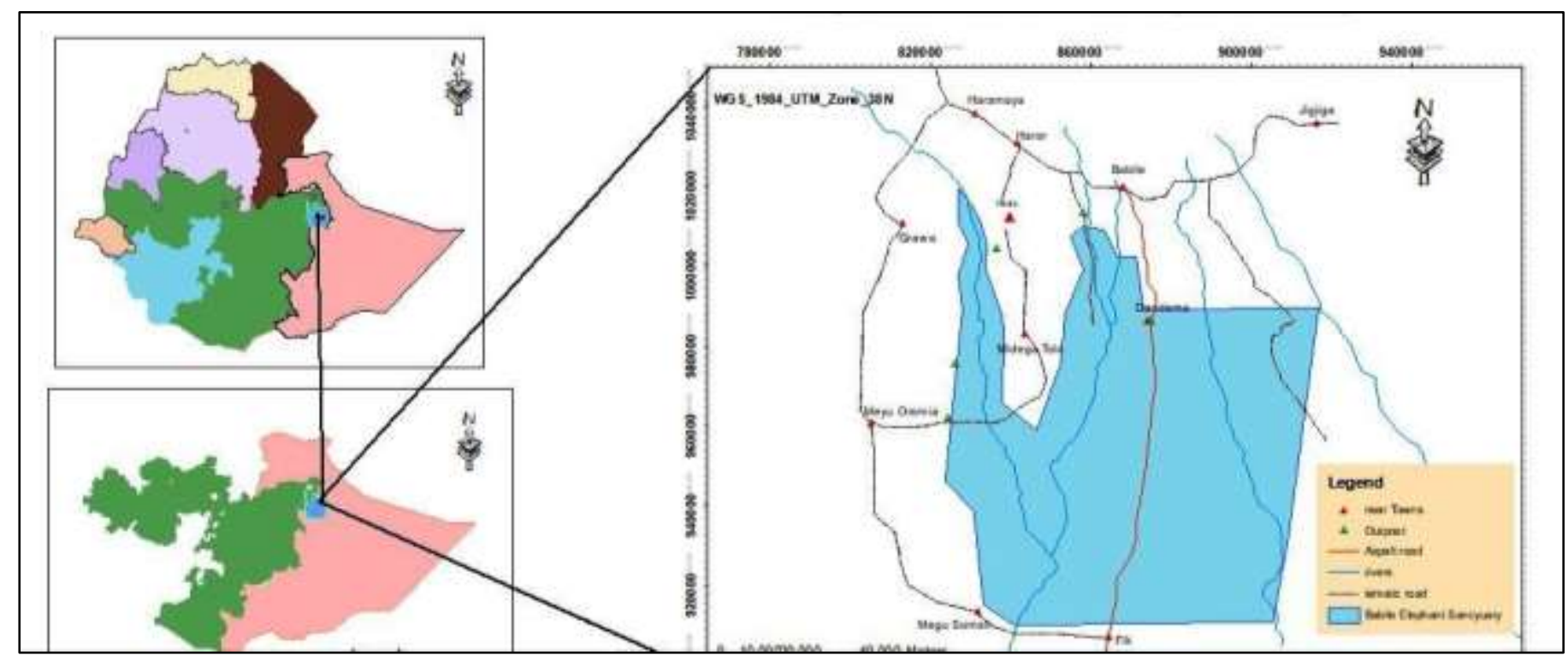

Figure 1. Map of Babile Elephant Sanctuary

The topography of the land has altitudinal ranges of $850 \mathrm{~m}$ to 1,785 m.a.s.l. About $84 \%$ of the sanctuary is described as flat to gentle slopes and $16 \%$ is composed of complex valleys and deep gorges (Yirmed Demeke, 2008). It is characterized by a semi-arid and arid climate. Has highest $\left(32.39{ }^{\circ} \mathrm{C}\right)$ and lowest $\left(9.66{ }^{\circ} \mathrm{C}\right)$ mean monthly temperatures. Rainfall distribution is bimodal (i.e., short rainy seasons- March to May and long rainy seasons- June to October). Has a high variation of rainfall (i.e., from 442 mm to $1302.9 \mathrm{~mm} / \mathrm{yr}$ ) with the mean annual rainfall of $802 \mathrm{~mm}$ (Source: NMSA data from 2002 to 2016). The total human population was 115,229; of which males $(57,463)$ and females $(57,463)$, and 90,415 (78.5\%) were the rural population. The district population density based on the population projected (2014-2017) was 36.4 persons $/ \mathrm{km}^{2}$; which was doubling in the year 1990 (i.e., 18.9 pers. $/ \mathrm{km}^{2}$ ) (FDRE/CSA, 2013). The increased population led to an increment in the demand for natural resources might lead to the expansion of human settlement. The communities livelihoods were depend on the mixed farming agriculture, characterized by crop and livestock production. Various crops such as vegetables, fruits, oilseeds, and cereal crops were produced. For instance, the cash crop "Chat" (Catha edulis) was mainly produced. Besides, livestock such as camels, cattle, sheep, goats, donkeys, and poultry along with oxen fattening were mainly produced. The vegetation of the sanctuary was represented by Acacia Commiphora woodland, semi-desert scrubland and evergreen scrub ecosystems and with high endemicity of various plants and grasslands (Yirmed Demeke et al., 2006). Due to altitudinal variation effects, rainfall variability occurred and a marked effect on the vegetation is observed (Yihew Biru and Afework Bekele, 2012). Generally, the vegetation of BES is divided into two major categories of riverine and woodland vegetation (Yirmed Demeke et al., 2006). However, presently due to anthropogenic impacts (e.g., deforestation), most of the woodland configuration/structure/ has been converted to bushlands. Mainly, the floristic composition of the sanctuary consists of shrubs and trees. In the sanctuary, shrubs have accounted for $94.9 \%$ while trees 
constituted only $5.1 \%$ of the total density (Tahir and Yeneayehu, 2017). Significantly has the high faunal composition (i.e., 30 mammals and 191 birds' species) (Hillman, 1993; Mihret Ewnetu et al., 2006) and it is one of the 73 important bird areas of Ethiopia; for instance, the endemic Salvadori's serin (Serinus Salvadori) and Agapor nistaranta (the Black-winged lovebird) (EWNHS, 1996). Besides, essential geological settings, physical and chemical compositions of soils which are important for the growth, diversity, and distribution of plant species were observed in the sanctuary (e.g., limestone, sandstone, gypsum, marbles, and anhydrite) (Mohr, 1964). And covered with (10\%) black soil, (2\%) clay soil, and (88\%) clay loam soils respectively (cited in Yirmed Demeke et al., 2006).

\subsection{Methods}

\subsubsection{Study Design}

Reconnaissance surveys were carried out during March 5/2020 and March 25/2020. During the surveys, discussions with concerned individuals at the sanctuary and local experts, information on elephant's movement pattern and impact of elephants, and anthropogenic impacts that contest the sanctuary were identified as a threat in addition to familiarizing self with the study area. Field observation and socio-economic survey through questionnaire survey and face to face, the interview (i.e., semi-structured interviews following the nature and extent of occurrence of the threats) were designed and conducted. Questionnaires were prepared in English language and translated to the local language "Afaan Oromo" and finally distributed to the local peoples. The selections of respondents were based on the purposive sampling technique. In the questionnaire survey, the key resource persons were the local peoples and other service delivering personals in BES (i.e., staff members). The survey encompassed interviews, participant observations, and the use of archive data (i.e., secondary data sources) to get an overview of conservation pressure. Based on the preliminary observation /survey, 5 districts (Babile, Fedis, Midhega tola, Mayu muluke, and Babile-Somale district) were purposively selected considering the proximity to the sanctuary as criteria. From the districts, in turn, the most nearby " Kebeles" (i.e., divisions within a district or Peasant Associations-PeAs) to the sanctuary based on prevalent occurrences of conservation extortion and other HEC incidents by comparing with other sites were considered (i.e., There were 20 "Kebeles"). In this study, 20 "Kebeles", each two to five Peasant Associations (i.e., "Kebeles") was selected from each district. From the "Kebeles" close to the sanctuary, respondents selected were Key Informants, (KIS) Focus group discussant (FGD), and Households (HHS).

\subsubsection{Data Collection}

For the actual data collection, primary and secondary data collection methods were used. The primary data collection was carried out through interviews and questionnaires prepared for this purpose. Besides, Data regarding current and historical levels of threats and HEC incidents were collected and investigated through interviews in the five study districts (i.e., Babile-Oromia, Midhega Tola, Fedis, Mayu muluke, and Somale-Babile) of PeAs. Moreover, secondary data from BES of Wildlife Office were taken. Thought of local peoples on incidents those were happened while conservation threats in each "kebeles" were perceived.

\subsubsection{Key Informant Interview and Focus Group Discussion}

Key informants from five districts ( 2 in each) were systematically selected and interviewed. They were worked in their "kebeles" leadership during different seasons, and know the status of the people in their corresponding sites. Moreover, development agents in the "kebeles" were also selected with the help of scouts of the BES. Five Focused Group Discussion (FGD) consisting of 15 individuals. They were composed of experienced 3 farmers in each "kebele" including the elderly, traditional leaders, and school youths. 5 groups, each having 15 individuals in each "kebele" were participated in FGD. The purpose of the FGD was to provide additional information following the nature and extent of occurrence of HEC. Therefore, group discussion, interviews were conducted.

\subsubsection{Households' Selection and Sampling Size Determination}

As farmers' ability to maintain and their knowledge in managing HEC on the agricultural landscape depend on the socio-economic status of the farmers and a wealth ranking that was used to stratify farmers' households for the selection purpose of sample households (Crowley, 1997). The key informants (KIs) helped in classifying farmers into socio-economic status. The criteria used by the key informants to classify the HHs into different wealth categories (poor, medium, and rich) were mainly based on the number of cattle, amount of annual crop production, and type/standard of housing. The key informant's wealth ranking method was used by classifying the number of livestock population (Table 1). 
Table 1. Average wealth ranking criteria have been done by the key informants among the selected five districts

\begin{tabular}{|c|c|c|c|c|c|c|c|c|c|c|c|c|c|c|c|}
\hline \multirow[t]{2}{*}{ Live stock } & \multicolumn{3}{|c|}{ Fedis District } & \multicolumn{3}{|c|}{ Mayu Muluke } & \multicolumn{3}{|c|}{ Midega tola } & \multicolumn{3}{|c|}{ Babile-Oromia } & \multicolumn{3}{|c|}{ Babile-Somale } \\
\hline & $\mathbf{R}$ & $\mathbf{M}$ & $\mathbf{P}$ & $\mathbf{R}$ & $\mathbf{M}$ & $\mathbf{P}$ & $\mathbf{R}$ & $\mathbf{M}$ & $\mathbf{P}$ & $\mathbf{R}$ & $\mathbf{M}$ & $\mathbf{P}$ & $\mathbf{R}$ & $\mathbf{M}$ & $\mathbf{P}$ \\
\hline Cows & $>7$ & $1-3$ & $\leq 1$ & $>20$ & 15 & $\leq 5$ & $>10$ & $6-8$ & $\leq 5$ & $>10$ & $5-10$ & $\leq 4$ & $>15$ & 15 & $\leq 5$ \\
\hline Donkey & $>2$ & $1-2$ & $\leq 1$ & - & - & - & $>2$ & $1-2$ & $\leq 1$ & $>5$ & $3-4$ & $1-2$ & $>2$ & $1-2$ & $\leq 1$ \\
\hline Goats & $>20$ & 15 & $\leq 4$ & $>20$ & 15 & $\leq 5$ & $>15$ & $10-15$ & $\leq 2$ & $>15$ & 15 & $\leq 5$ & $>35$ & 20 & $\leq 5$ \\
\hline Sheep & $>4$ & $1-3$ & $\leq 1$ & 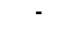 & - & - & $>8$ & $5-8$ & $\leq 5$ & 15 & $5-8$ & $\leq 2$ & - & - & - \\
\hline Camels & $\geq 1$ & $\leq 1$ & - & $>20$ & 15 & $\leq 5$ & $\geq 7$ & $5-7$ & $\leq 2$ & $>5$ & $2-4$ & $\leq 1$ & $>15$ & 10 & $<5$ \\
\hline Hens & - & - & - & - & - & $<5$ & $>15$ & $5-10$ & $<5$ & $>20$ & 15 & $\leq 5$ & $>15$ & 10 & $<5$ \\
\hline
\end{tabular}

Key: R= Rich, $\mathrm{M}=$ Medium and $\mathrm{P}=$ poor; Greater than $(>)$, Less than $(<)$, Greater than or equal to $(\geq)$, Less than or equal to $(\leq)$

A random selection procedure was used to obtain samples of individual HHs from each wealth category to have a systematic approach. Irrespective of whether there are HEC victims or not summing up to $138 \mathrm{HHs}$ interviewed in five districts of their corresponding "kebeles" around the boundary of the sanctuary (Table 1). A semi-structured questionnaire was administered to respondents aged 25 years and above, who had lived in the respective location for at least five years or more. A stratified sampling procedure was used to obtain samples of individuals HHs from each wealth category. The population of study areas was taken from the members' register of 2020. The total Households of the 20 "kebeles" were 32,829; of which 5594, 11,139, 7139, 1575, and 7382HHs were for Oromia-Babile, Fedis, Midega tola, Mayu muluke, and Somale-Babile districts respectively (Table 1). The list of an ultimate sampling sample frame of the household living in 20 "kebeles" holds persons who own at least a plot of farmland of their own. The number of sampled HHs that were included in the study areas was determined from the sampling frame following Kothari (2004).

The formula to determine the sample size for a finite population is indicated below.

$$
\mathrm{n}=\frac{\mathrm{Z}^{2} * \mathrm{p} * \mathrm{q} * \mathrm{~N}}{\mathrm{e}^{2}(\mathrm{~N}-1)+\mathrm{Z}^{2} * \mathrm{p} * \mathrm{q}}
$$

Where, $\mathrm{n}=$ sample size,

$Z=95 \%$ confidence limit (interval) under the normal curve, i.e. 1.96.

$\mathrm{p}=0.1$ (proportion of the population to be included in the sample, i.e.10\%)

$q=$ non-occurrence of event which is equal to (1- 0.1), i.e. 0.9.

$\mathrm{N}=$ Total number of population or Households

$\mathrm{e}=$ margin of error or degree of occurrence (acceptable error term) 0.05.

Based on the above formula after calculation, the sample size of the household members that were subject to 20 "kebeles" of study areas was $138 \mathrm{HHs}$. All of the HHs from each of the three stratified wealth categories in the "kebeles" was interviewed. Based on wealth ranking, about $84 \%$ of the sampled $\mathrm{HH}$ farmers in the study areas are medium and poor farmers, indicating a subsistence type of farming system and livestock production for earning their livelihood income. In general, from the total sampled HHs (138HHs), $16 \%$ was rich, $36.2 \%$ was medium and (47.8\%) was poor (Table 2 ).

\begin{tabular}{|c|c|c|c|c|c|c|c|c|c|c|}
\hline \multirow[t]{2}{*}{$\begin{array}{l}\text { Name-of } \\
\text { districts }\end{array}$} & \multirow[t]{2}{*}{$\begin{array}{c}\text { Name of PeAs } \\
\text { /Kebelles/ }\end{array}$} & \multirow[t]{2}{*}{$\begin{array}{c}\text { Total } \\
\text { Pop.no. }\end{array}$} & \multirow[t]{2}{*}{$\begin{array}{c}\text { Total } \\
\text { no.of } \\
\text { HHs }\end{array}$} & \multicolumn{3}{|c|}{$\begin{array}{l}\text { No. of HHs based on } \\
\text { wealth status }\end{array}$} & \multicolumn{4}{|c|}{ No.of selected sampled HH } \\
\hline & & & & $\mathbf{R}$ & $\mathbf{M}$ & $\mathbf{P}$ & $\mathbf{R}$ & $\mathbf{M}$ & $\mathbf{P}$ & Total \\
\hline \multirow[t]{4}{*}{ Babile (Oromia) } & Erer ebada & 8851 & 1490 & 149 & 596 & 745 & 1 & 2 & 3 & 6 \\
\hline & Ebada Gamachu & 9655 & 1559 & 187 & 592 & 780 & 1 & 3 & 3 & 7 \\
\hline & Gamachu & 7750 & 1350 & 135 & 540 & 675 & 1 & 1 & 3 & 5 \\
\hline & Berkele & 7660 & 1195 & 84 & 418 & 693 & 1 & 1 & 3 & 5 \\
\hline \multirow[t]{5}{*}{ Fedis } & Anani & 4528 & 1132 & 283 & 396 & 453 & 1 & 2 & 2 & 5 \\
\hline & Bidibora & 6504 & 1227 & 184 & 491 & 552 & 1 & 2 & 2 & 5 \\
\hline & Umerkule & 7608 & 3790 & 758 & 1327 & 1705 & 2 & 7 & 8 & 17 \\
\hline & Agidoraa & 6856 & 1945 & 292 & 778 & 875 & 1 & 3 & 4 & 8 \\
\hline & \multicolumn{10}{|c|}{ Cont... } \\
\hline
\end{tabular}

Table 2. The number of selected HHs based on wealth status for the study 
International Journal of Research in Agriculture, Biology \& Environment (ijagri), Vol. 2 (4), Oct -Dec - 2021

\begin{tabular}{|c|c|c|c|c|c|c|c|c|c|c|}
\hline & Negaya bobasa & 7440 & 1566 & 157 & 626 & 783 & 1 & 3 & 4 & 8 \\
\hline & Qufa bobasa & 7027 & 1479 & 400 & 500 & 579 & 1 & 2 & 3 & 6 \\
\hline \multirow[t]{6}{*}{ Midhega tola } & Negaya Midhega & 7267 & 762 & 169 & 273 & 320 & 1 & 1 & 1 & 3 \\
\hline & Bilisuma & 6267 & 865 & 203 & 307 & 355 & 1 & 1 & 1 & 3 \\
\hline & Qarensa & 3890 & 722 & 153 & 264 & 305 & 1 & 1 & 1 & 3 \\
\hline & Lencha & 17043 & 2012 & 201 & 805 & 1006 & 1 & 3 & 4 & 8 \\
\hline & Barzalaa & 8147 & 895 & 223 & 402 & 270 & 1 & 2 & 1 & 4 \\
\hline & Qufaa & 4387 & 1883 & 188 & 660 & 1035 & 1 & 3 & 5 & 9 \\
\hline \multirow[t]{2}{*}{ Mayu muluke } & Alola & 955 & 787 & 93 & 240 & 454 & 1 & 1 & 1 & 3 \\
\hline & Gebdida & 1030 & 788 & 157 & 276 & 355 & 1 & 1 & 1 & 3 \\
\hline \multirow[t]{3}{*}{ Babile somale } & Dandema & 25000 & 4000 & 680 & 1205 & 2115 & 2 & 7 & 8 & 17 \\
\hline & Bikkoo & 19500 & 3382 & 507 & 1184 & 1691 & 1 & 4 & 8 & 13 \\
\hline & Total & 167365 & 32829 & 5203 & 11880 & 15746 & 22 & 50 & 66 & 138 \\
\hline
\end{tabular}

\subsection{Materials Used}

Materials such as Standard questionnaires, relevant published and unpublished literature, topographic map of the area and its surroundings, computer, calculator, GPS handset, binoculars, digital camera, measuring tape, and compass were used for this study.

\subsection{Data Analysis}

The data were analyzed by using simple descriptive or qualitative and quantitative or numerical methods. The data and/or information that were collected for the objective of conservation threats (e.g., human-elephant interaction), based on the data and information collected about the history, type, nature of the threats and causes from the questionnaire survey (i.e., the in-depth information) obtained based on people's perceptions and attitudes were summarized and interpreted through descriptive statistics (such as percentage and frequency) to understand different trends. Besides, the Chi-square test $(\chi 2)$ was handled on the frequency of reported HEC in all study allocations for all years and the kind of conflicts that were reported in BES over the consistent past five years. At last, the outcomes were interpreted or represented using tables, graphs, and charts.

\section{RESULTS AND DISCUSSION}

\subsection{Demographic and Socio-Economic Characters}

The study sites (20 PeAs) hold an average land of 1.48ha (Table 3). In education status, according to respondents viewed, more than $55 \%(\mathrm{~N}=542 \mathrm{HHs})$ were illiterate and about $45 \%(\mathrm{~N}=443 \mathrm{HHs})$ of them were literate (Table 3). However, among the literate groups, about $42.3 \%(\mathrm{~N}=417 \mathrm{HHs})$ and $2.7 \%(\mathrm{~N}=26 \mathrm{HHs})$ of respondents were educated with primary \& secondary school level status respectively (Table 3). The average family size is 5 (Table 3). And, the entire HHs head's according to all (100\%) of the respondents; the livelihood of people in the area comes from agriculture. Among those; only land cultivators $(\mathrm{N}=482,49 \%)$ and livestock production $(\mathrm{N}=272,27.6 \%)$; while both activities of the land cultivators and livestock husbandry $(\mathrm{N}=231,23.4 \%)$ were engaged. In general, the religions of the study sites were dominated by Muslims (100\%); having an ethnicity of Oromo (91\%) and Ethio-Somale (9\%) (Table 3).

Table 3. General Socio-economic character of the study sites areas (including all/20 PeAs)

\begin{tabular}{lllcc}
\hline S/N & Socio-economic character & Unit & Total & Total average/PeAs \\
\hline 1 & Sex & Pop. & & \\
& Male & No. & 93,220 & 4661 \\
& Female & No. & 74,145 & 3707 \\
& Total sum & No. & 167,365 & 8368 \\
3 & Number of house holds & No. & & \\
& Male & No. & 23363 & 1168 \\
& Female & No. & 9466 & 473 \\
& Total sum & No. & 32829 & 1641 \\
4 & Average landholding size & Ha & - & 1.48 \\
5 & Average family size & No. & - & 5 \\
6 & Average Age & Year & - & 41 \\
& & & & \\
\hline
\end{tabular}




\begin{tabular}{|c|c|c|c|c|}
\hline \multirow[t]{5}{*}{7} & Education status level & & & \\
\hline & Cannot read and write & $\%$ & - & 55 \\
\hline & Can read and write & $\%$ & - & 45 \\
\hline & Elementary school (1-8 grade) & $\%$ & - & 42.3 \\
\hline & High school (9-12 grade) & $\%$ & - & 2.7 \\
\hline \multirow[t]{4}{*}{8} & Occupation & & & \\
\hline & Land cultivators/tillers & $\%$ & - & 49 \\
\hline & Livestock production & $\%$ & - & 27.6 \\
\hline & Both & $\%$ & - & 23.4 \\
\hline \multirow[t]{2}{*}{9} & Religion & & & \\
\hline & Muslims & $\%$ & - & 100 \\
\hline \multirow[t]{3}{*}{10} & Ethnicity & & & \\
\hline & Oromo $(\%)$ & $\%$ & - & 91 \\
\hline & Ethio-Somale & $\%$ & - & 9 \\
\hline
\end{tabular}

\subsection{Conservation Threats}

Natural and human-induced impacts can affect the conservation areas. However; in this study, various anthropogenic challenges/human-induced effects were predominantly observed in the study areas (Figure 1). About 121(87.7. \%) respondents' picture HEC was the major source of threats in the study sites area (Table 4). According to respondents answered poachers entered a sanctuary to kill elephants; throughout this time some elephants speed up from sanctuary to nearby farmlands then crop-raiding occurred as a revenge of the poachers. For instance, as respondents replied while HEC occurs in all study areas (i.e., from 20PeAs) about 19 elephants, 24 livestock, and 22 local peoples have died within the last five years (2016-2020). Besides, elephants damaged various irrigation materials, food stores, and crop-raiding was observed in the study areas. Of all respondents, 108(78\%) oppose the existence of the elephant conservation system (i.e., this might cause the widespread incidence), while $30(22 \%)$ stated the existence (Table 4). There was a significant difference in the view of a local community to HEC especially (e.g., crop-raiding) $\left(\chi^{2}=7.8, D F=3, P<0.05\right)$. More than $82 \%$ of total respondents thought that deforestation; settlement, charcoal production, agricultural expansion, and livestock grazing were the major problems that hinder the conservation work of the sanctuary as indicated below in (Table 4). For instance, some of the impacts were observed during data collection in some study areas of the sanctuary were indicated below (Figure 2).

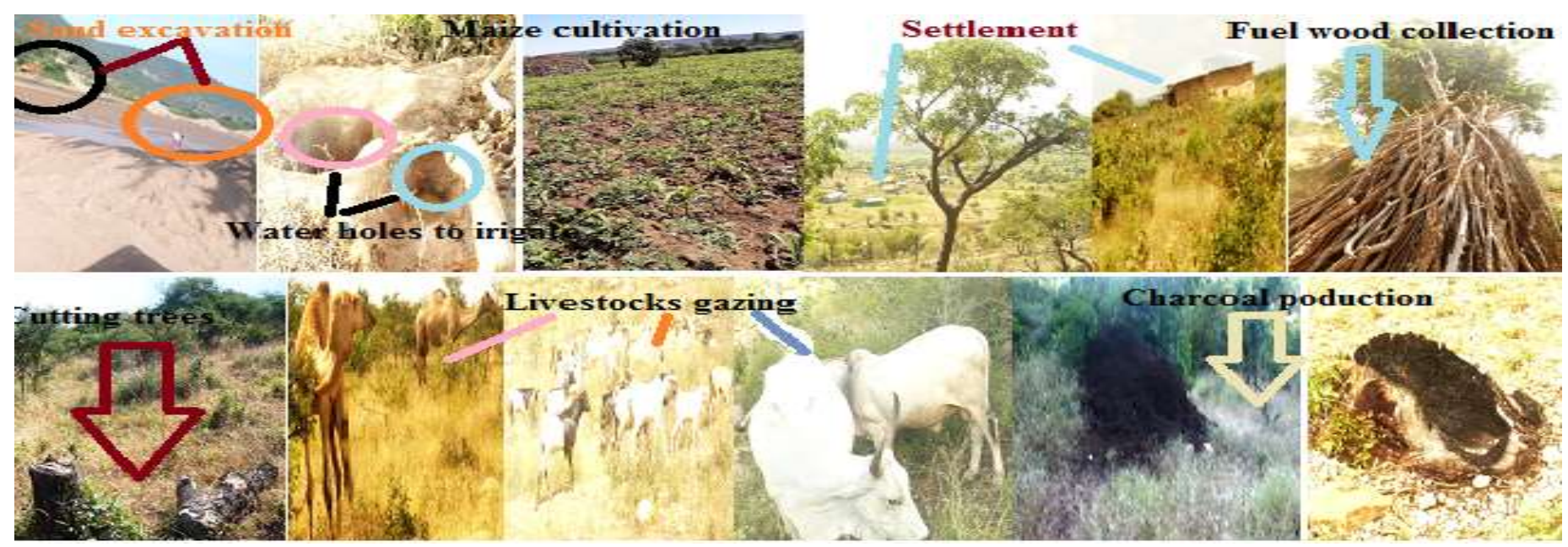

Figure 2. Some of the anthropogenic impacts in the sanctuary that were observed (photo taken)

Less than $62(45 \%)$ of respondents also viewed, hunting of some wild animals like common bushbuck (Tragelaphus scriptus), lesser kudu (Tragelaphus imberbis) and greater kudu (Tragelaphus strepsiceros) were common in the sanctuary. However; hunting is insignificant threats for conservation relatively with other $(\chi 2=30, D F=19, P<0.05)$. According to (43\%) and (35\%) of respondents respectively were viewed as an absence of good management capacity of the sanctuary as well as the involvement of stakeholders \& partners were some challenges to the conservation. There was insignificant difference in fuelwood collection $(\chi 2$ =22.5, $D F=19, P<0.05)$, in management capacity $(\chi 2=8.9, D F=19, P<0.05)$, and involvement of stakeholders $\&$ partners $(\chi 2$ =3.72, $D F=19, P<0.05)$ to reduce the conservation challenges in the sanctuary. However; most of the conservation challenges were significant (Table 4). According to 80 (58\%) of respondents viewed, there was some excavation of sand occurred in the sanctuary, mainly when less patrolling occurred and low law enforcement and additionally lack of effective stakeholders and 
partners' involvement occurred in the sanctuary (Table 4). However; excavation of sand affects significantly $(\chi 2=63.98, D F=19$, $P>0.05)$ while the wild animals' heard a noisy sound during truck moves to load sand in the sanctuary. More than half (50\%) of respondents also viewed as poaching, illegal (uncontrolled) fire, and expansion of invasive species threats (i.e., Lantana camara and Parthenium hystrophorus were dominant in the sanctuary) and were other challenges in the sanctuary conservation works (Table 4). And, even, there were significant poaching $(\chi 2=344.43, D F=19, P>0.05)$ and illegal fire $(\chi 2=110.08, D F=19, P$ $>0.05$ ) were observed in the sanctuary. In general, the observed conservation threats in BES were grouped into internal (i.e., less human, logistic, and technical capability) and external factors (i.e., less participation of stakeholders, partners, and other conservative bodies) and discussed in detail below.

Table 4. Perception of respondents' on conservation threats that are occurred in BES $(\mathrm{N}=138)$

\begin{tabular}{llcc}
\hline S.N & Conservation threats/ challenges & Frequency and \% of respondents (N=138) & Percentage (\%) \\
\cline { 3 - 3 } & & Frequency (number) & 100 \\
2 & Human population growth & 138 & 89.13 \\
3 & Settlement & 121 & 87.7 \\
4 & Human-elephant conflict & 120 & 86.96 \\
5 & Deficultural expansion & 117 & 84.78 \\
6 & Livestock grazing & 114 & 82.6 \\
7 & Charcoal production & 113 & 81.9 \\
8 & Poaching & 110 & 79.71 \\
9 & Less community participation & 97 & 70.29 \\
10 & In effective law enforcements & 93 & 67.4 \\
11 & Illegal (uncontrolled) fire & 90 & 65.22 \\
12 & Excavation of sands & 80 & 57.97 \\
13 & Fuel wood collection & 79 & 57.24 \\
14 & Expansion of invasive species & 70 & 50.72 \\
15 & Hunting (i.e., other than elephants) & 62 & 44.93 \\
16 & Lack of management capacity & 60 & 43.5 \\
17 & Ineffective stakeholders \& partners involvement & 48 & 34.78 \\
18 & Support the existence elephant conservation & 30 & 22 \\
\hline
\end{tabular}

\subsubsection{Human Population Growth}

All of the respondents $(100 \%)$ viewed that Human population growth is the major threat or challenge for the sanctuary; the population was widely increased as the result of land shortage for existing and needing to exploit the resource as respondents replied. The reason why various human-induced conservation threats (for instance, as-settlements, deforestation, and overgrazing, poaching, and less participation of local community) were expanded in BES might be linked to human population growth (Table 4) and low productivity of the land. The high human population and the growing trend can be observed around sanctuary due to the need to cultivate the land and pasture for grazing their animals (Table 4). Similarly, United States Agency for International Development (USAID) (2008) was also reported, as human population growth around the protected areas could offer drives and aggravate the effects of the others challenges through greater pressure on the land and resources to provide for immediate human needs. In this study, all $(100 \%, \mathrm{n}=138)$ of respondents were thought; populations were increasing around and inside the sanctuary for a competition of land, water, and other resources (Table 4). This finding is similar to Ashenafi et al.(2005), Human population growth can be a cause for other activities such as settlement, agricultural expansion, habitat loss/destruction, overgrazing, deforestation, soil degradation, and misuse of natural resources. In general, Human population growth around the sanctuary was increased for the need of exploiting the natural resources. Therefore, communities' awareness creation and family planning methods are necessary to manage the population explosion threats to the sanctuary.

\subsubsection{Settlement}

People temporary and permanent settlements (i.e., either inside or peripheral part of the sanctuary) were influencing the conservation activities. The most heavily settled areas were districts that follow the Valleys of Gobele (Midega tola, Fedis, Mayu muluke) and Erer Rivers (Oromia-Babile and Somale-babile/Dandama). In this study, 89.13\% of respondents viewed as local people, who were coming from far and nearby districts and who were settled in the sanctuary were affecting the conservation works (Table 4). Due to this, elephants and humans were encountered severely. For instance, Anteneh Belayneh and Sebsebe Demesew (2011) were reported that about 31 small villages have encroached inside the sanctuary. Similarly, Yirmed Demeke 
(2008) also reported, that the growth of the human population in the area, the influx of refugees, the establishment of state farms, and villagization campaigns during the Dergue Regime were affecting the conservation works. Many people live within and/or the sanctuary boundaries, increasing pressure on the natural resources of the area and diminishing natural habitats of wild animals and most of the sanctuary were encroached by settlements. The settlement could be one of the most conservation threats acted as the driver of deforestation (eg. due to the need for cultivating the land) in the sanctuary (Table 4).

\subsubsection{Human-Elephant Conflict}

In Ethiopia, in all wildlife-protected areas, human-wildlife interaction occurs, but in the areas where elephants are present, the interaction becomes more. HEC was the main encounter or threat of conservation works in the sanctuary as $87.7 \%$ of respondents were perceived (Table 4). Human-elephant interaction showed that elephants have negatively influenced local commutes attacking and killing humans and livestock, destroying irrigation materials, food stores, and crops. This finding is similar to (Bal et al., 2011) (Santiapillai, 2010) which have shown that the amount of devastation of the elephants ranges from severe crop-raiding to killing of people, in which the species develop the gravest and detrimental. Similarly, Sintayehu et al. (2016) reported that BES had faced a disastrous situation due to HWC. Even, the data obtained from the Annual report of BES in 2018 indicated that, due to HEC reasons, about 57 elephants and 12 people have died as well as 4 people were injured within 3 years (2013-2015), due to the absence of a warden in the sanctuary and very less supervision at all during the years in the sanctuary. However; in this study, as respondents replied from 20PeAs and data collected from BES office showed that about 19 elephants, 24 livestock, and 22 local people have died within the last five years (2016-2020). Therefore, in this study, the HEC was smaller when compared with past years, even though the impact has occurred. Besides, from observation during the present study, various crops (such as vegetables, fruits, oilseeds, and cereal crops) were spoiled by elephants during the day and night periods in all study sites (i.e., 20 PEAs; for instance in Erer ebada, Anani, Bilisuma, and Alola) "kebeles" due to trampling. This finding was similar to (Sitienei and Ngene , 2014), who reported that elephants and other wildlife can damage most crops in a field a single day or night. Therefore, HEC has to be handled to save the sanctuary and nearby communities resources.

\subsubsection{Deforestation}

Deforestation in Ethiopia is closely linked to the ongoing population growth. More people generally lead to an increasing demand on land for living and agricultural production. In this study, deforestation (habitat destruction) is a serious challenge in the sanctuary as the result of making charcoal production, fuelwood collection, and agricultural activities (Table 4). Even, in this study, about $87 \%$ and $85 \%$ of respondents respectively were viewed as agricultural expansion, and deforestation was expanded due to people settlement inside and/or nearby boundaries. Similarly, findings by Yirmed et al. (2006) indicated that the home range of elephants in BES has shrunk by about $65.5 \%$ since 1976 (i.e., the rangeland of the Yerer-Dakota valley); due to the mass influx of a large number of farmers and their livestock along the east and north of the sanctuary. Similarly, Sintayehu Workeneh et al. (2016) also reported that the sanctuary habitats in general and natural vegetation of the Yerer valley, in particular, are being exploited in a destructive and unsustainable manner. For instance, Anteneh Belayneh and Sebsebe Demesew (2011) were also reported that about 400 ha of land along the Erer River and some areas (20ha) of woodland in a different part of the Erer Valley were cleared illegally for agricultural purposes. This finding is similar to Berry (2003) due to the need for cultivated land, wood for fuel, and construction materials were increased deforestation. Solomon Chanie and Dereje Tesfaye (2015) and World Bank (2011) also reported that a human settlement around protected areas might be a primary driver of deforestation. For instance, Demel Teketay (1995) also reported that the expansion of agricultural activities southward to the innermost part of the sanctuary had continued for the last 30 years. Communities in the vicinity of the valley are engaged partly in pastoralism and use the valley for livestock grazing and for cultivating sorghum, maize, and peanuts. In general, the negative impacts of human settlements due to human activities (such as livestock grazing, agricultural expansion, and others) were changing the land coverage or the territories of the wildlife resources in the sanctuary. Therefore, measures have to be needed to worsen the forest's destructive and unsustainable manner of practice to revive the existence of the sanctuary.

\subsubsection{Livestock Grazing}

Around BES, Livestock grazing is the oldest and common practice occurred by local peoples, mainly Ethio-Somali pastoralists. In this study, $114(82.6 \%)$ of respondents were perceived that overgrazing by livestock was a serious conservation challenge in the area; however, in the past, it is limited (Table 4). Elephants are known to be easily disturbed as the result of invasion by livestock making them nervous. Similarly, Yirmed Demeke (2008) reported, at least 2,200 numbers of cattle and 3,350 numbers of camels were daily competing with Elephants in the Upper Erer Valley of the BES. However, Stephenson (1976) reported, as there was the limited competition between pastoralists and Elephants in the valleys, in the earlier years of the establishment of BES. Grazing by livestock may affect the quality of the habitat for the wildlife community. It is a serious challenge when lack of free space for animal movements while increasing human settlements have occurred in the sanctuary. The impact was more especially in the 
pastoralist areas, where their livestock moves seasonally into the sanctuary for finding grass and water and due to the absence of buffer zone, the vegetation around the edges was affected and this finding is similar to Negese Nako (2014) as the edge of the protected areas was affected by livestock overgrazing. Vial et al. (2011) was also reported as, livestock grazing (i.e., very intense), and population growth in the protected areas was threatened directly by encroaching the wildlife area. Livestock grazing as devastating practice in the country (Duckworth, 2002) and as one of the challenges in the protected areas (Solomon Chanie and Dereje Tesfaye, 2015) and in particular in BES, communities in the proximity of the valley are engaged relatively in pastoralism and use the valley for livestock grazing. So, the overgrazing issue is one of the challenges that were faced on the sanctuary that needs handling.

\subsubsection{Ineffective Community Participation}

Less community participation is also another problem that might hinder or influence the conservation activities. Negative attitude towards elephants conservation was more frequent in areas surrounding the sanctuary and people believed that these animals were worthless as they attacked people, cattle and destroyed crops. In several instances, local people were simply afraid of them and were negatively inclined towards their continued presence. In this study, 97(70.29\%) of respondents thought, as there was less/lack of community participation in the sanctuary, due to lack of benefit obtained from the sanctuary (Table 4). Similarly, Solomon Abebe (2014) reported that there were no benefit sharing and a lack of community participation in most wildlife-protected areas of the country. Participation of local people in the conservation activities was decreasing due to low knowledge on the benefit of wildlife and the absence of enough benefit share (Table 4). But, occasionally, during wildlife census, developmental activities (e.g., road construction and maintenance), management plan preparation, and different meetings, the local communities participated. There was an absence of respecting their rights and responsibility, mutual interests, sharing benefit fully and equitably in connection with protected areas and this similar result was also reported by Soromessa (2007) as a benefit was absent to the local community and local communities were brought an impact to many protected areas during the change of Government in 1991. USAID (2008) and Carey et al. (2000) were also reported as due to fewer communities' ownership and unfair distribution of income or absence of benefit-sharing causes for many protected to be forcedly impacted and entered into degradation. So, effective participation with the local community \& sharing benefits is necessary to reduce the impact for the future.

\subsubsection{Poaching}

Poaching of elephants for ivory has been the major cause of the disappearance of elephants in Ethiopia, mainly in the east, south, and southwest regions. Regardless of the occurrence of hunting throughout the $20^{\text {th }}$ century, and the large number of elephants slaughtered in the 1990s was unjustifiable. Such a population crash was especially noticeable in the Babile Elephant Sanctuary, eastern Ethiopia, and Mago National Park, south Ethiopia. During its establishment of Mago and Babile, they were rich in wildlife (Yirmed Demeke, 2008); for instance, Mago National Park is known for the presence of more than 81 species of mammal and 236 species of birds (Hillman, 1993) and it might be one of the prosperous areas in the occurrence of large mammal numbers. In the first two decades of BES establishment, there were very effective management and law enforcement operations and government support for conservation. However, from the 1990s onwards, the situation was reversed and intensive killing of elephants for ivory became uncontrolled (Sintayehu Workeneh et al., 2014). Illegal ivory trade and poaching are currently the major global threats to elephants. Poaching is one of the severe conservation challenges that was occurred due to human expansion, loss, and fragmentation of habitat, and rapid land conversion in the sanctuary and its trend also increasing from time to time especially in Elephant Range State (Table 4). This finding is similar to Solomon Chanie and Dereje Tesfaye (2015) as; poaching was a challenge for the wildlife conservation works in the protected areas. Poaching for ivory has been the major cause for the reduction of elephants in the country in particular and specifically in the study sites (BES). Even, Illegal ivory trade and poaching are currently the major threats to elephants in the country. In this study, $79.71 \%$ of respondents were thought that elephants were killed occasionally by poachers in the sanctuary and brought a reduction in elephant population. Similarly, Sintayehu et al. (2016) were also reported as there were about 47 elephants in BES were died due to poaching and aggravated the situation to the already declining elephant population and other wildlife resources in the sanctuary. Zelalem Wodu (2007) and Yirmed Demeke (2008) were also reported as poaching for ivory and competition of wildlife with a large density of livestock was brought deterioration of habitat quality in BES. So, there has to be strong coordination between the protection staff and law enforcers (patrol activities) to reduce the impact.

\subsubsection{Illegal Fire}

Illegal (uncontrolled) fire impacts the vegetation resources increasingly to make charcoal and other agricultural activities in the sanctuary. In this study, $65.22 \%$ of respondents were viewed there were sometimes occasional illegal fires were practiced by the nearby community in the sanctuary (Table 4). The uncontrolled fire either wildfire or fire bypass the traditional practices might cause deforestation (Table 4). In this study, about $82 \%$ and $57 \%$ of respondents were thought that there was a significant charcoal production and some fuelwood collections were practiced respectively in the sanctuary (Table 4). For instance, Anteneh Belayneh 
and Sebsebe Demesew (2011) were reported that about 735 sacks of charcoal production, 625 bundles of firewood, and cutting of 680 trees for house construction in the Erer Valley were observed in the sanctuary. Charcoal production is a great challenge in the sanctuary; mainly the local peoples have used Acaccia species for charcoal production. This finding was similar to Anteneh Belayneh and Sebsebe Demesew (2011) reported, Acacia mellifera, Acacia tortilis, and Acacia Senegal were the targeted key species for charcoal burning in the sanctuary. Similarly, Anteneh Belayneh (2006) explained that local people generate alternative revenue, they destruct the native plants and also reduce their pastoral lifestyles. Desalegn Wana (2008) was also reported as; local people around protected areas practice burning before the rain. Even, in Senkele Swayne's hartebeest Sanctuary, the savannah ecosystem yearly burned part by part to generate enough and new emerging grass for the Swayne's hartebeest food. Solomon Chanie and Dereje Tesfaye (2015) also reported as illegal fire is severe in the protected area where pastoralists' predemonentally occurred for preparation of new emergence of grass to their livestock. Since severe burning practices can destroy trees and grasses at the early stages of their growth there has to be prescribed fire management for the future to save them.

\subsubsection{Invasive Plant Species}

Invasive plant species like Lantana camara, Prosopis juliflora, and Parthenium hystrophorus are the other threats that were noted during field observation. During field observation, the local people and key informants were explained that Lantana camara was creating problems since it was introduced during the 1980s. In this study, more than $50 \%$ of respondents were thought that there were invasive species (i.e., species that were dominating other native fauna and flora) in the sanctuary (Table 4). Similarly, Binggli and Desissa (2003) reported that it prevents the growth of other trees and plants. For instance, Lantana camara is a weed not used by animals as fodder or human being for any productive purpose. Presently, it is rapidly covering mainly the grazing land of the sanctuary and becoming a major threat to the grassland (i.e., the main feed source for the elephants). Binggli and Desissa (2003) reported that this invasive species is less prone to be eaten by elephants and livestock due to its toxicity and further inhibits competing plant species. And, it is also used as a shelter for threatening wild animals like wild cats, hyenas, warthog, and others. In this study, Lanthana camara was highly distributed in the riverine habitats; however, there was little in the woodland habitat. But, a multitude of seedlings of Parthenium hystrophorus invasive species was observed scattered in all three land units (i.e., rivers, woodland, and bushland) of the sanctuary were observed while field observation practiced. Similarly, Anteneh Belayneh and Sebsebe Demesew (2011) were reported that Lantana camara was recorded in 43 of the 75 quadrats in the sampled taken in BES; 2,795 individuals per ha of which 1,035 individuals/ha were seedlings accounting for $37 \%$ of its total density. In general, the number of regeneration of observed Lantana camara showed the severity of invasion in the sanctuary. For instance, during field observation, the Northern upper part of the Erer Valley was covered by Lantana camara in most land features including the riverbanks, field plains, and hillside areas were observed. If the infestation rate continues, it will be a major threat and might dominate the natural vegetation in the BES. Of course, some initiation was observed while data collection; local peoples cut Lantana camara from the base before it flowers and burn it on-site afterward. This might show, the local communities understood the negative effects. So, strong measures have to be needed to reduce the expansion rate.

\subsubsection{Ineffective Management Capabilities}

There were also different management capacities inabilities were faced while managing the wildlife resources in the protected areas and its trend also increased from time to time. In this study, 93 (67.4\%), 60 (43.5\%), and 48 (34.78\%) of respondents respectively were thought that there was a lack of effective law enforcement, lack of management capacity, and lack of effective stakeholders and partners involvement was observed as a conservation challenge in the sanctuary (Table 4). Similarly, SDPASE/EWCA (2015) reported that there was a lack of management capacity due to internal and external challenges faced. Therefore, particularly in Ethiopia and specifically in BES, there has to be effective enforcement of protected areas authorities' measures to be practiced on different angles of management aspects for reducing the conservation threats that were observed.

\section{CONCLUSION}

The result of this paper based on respondents' perception revealed that though conservation activities had a long history in Ethiopia in general and particularly in the study area of BES, however; the conservation of wildlife in the sanctuary has been threatened/ challenged mainly by various anthropogenic factors such as human population growth around sanctuary, settlement, HEC, agricultural expansion and less participation of local communities were the major distinguishable threats leading to wildlife habitat destruction. Not only negatively influenced the existence of the sanctuary but also the HEC threats affect the living condition of the nearby local communities through crop-raiding, human and elephant deaths, and injuries through poachers along with depredation of livestock. Other challenges were also increasing such as overgrazing by livestock, lack of law enforcement and management capability, and invasive species that influence the sanctuary. Since conserving the sanctuary resources and generating considerable income from the sector to the country's GDP are important; there has to be a multi-dimensional approach or strategic solution issues to be set up and involving effective participation of different stakeholders, partners, higher institutions, and others nature 
conservative groups to save the BES resources and their habitats from anthropogenic damage and ultimately to sustain the importance (opportunities) that are obtained.

\section{ACKNOWLEDGEMENT}

Primarily, we would like to express our gratitude to the Eastern Harerge Zone districts and Kebeles offices of study areas for their valuable assistance to manage the focus group discussants. Besides, we thank the key informants and the focus group discussants and individuals who assisted during data collection. Our special thanks also go to the staff and scouts of BES who assisted during data collection.

\section{DECLARATION}

Abbreviations: NMSA-National Meteorological Service Agency, EWNHS-Ethiopian Wildlife Natural History Society, HECHuman-Elephant Conflict, BES-Babile Elephant Sanctuary, HHs-Households, FGD-Focus Group Discussion, PeAs-Peasant Associations, PAs-Protected Areas, SDPASE/EWCA-Sustainable Development of Protected Area System of Ethiopia/Ethiopia Wildlife Conservation Authority

Competing interest: The authors declares that they have no competing interests

Ethical approval and consent to participate: Not applicable

\section{Consent for publication: Not applicable}

Funding: Addis Ababa University for its financial support.

Authors' contribution: Data collection, analysis, preparing the draft paper was contributed by corresponding author while finalizing and approving the whole document were made by both authors.

\section{Authors Information:}

1. Taye Lemma Geleta was born in Oromia regional state of Ethiopia in 1976 G.C. has an educational level (Ph.D. candidate in AAU, and had received MSc, BSc and diploma related to NRs. Presently working in Ethiopia Wildlife Conservation Authority in Addis Ababa. And, currently, married and has two sons.

2. Associate professor Girma mengesha (Ph.D) was a college dean for the past years in Wondo Genet College of Forestry and Natural resources, Hawassa University. And, presently he works on Addis Zoo Park in sedestkilo lion sanctuary Addis Ababa city and also serving as adjunct lecturer in Addis Ababa University.

\section{REFERENCES}

Anteneh Belayneh (2006). Floristic description and Ethno botanical study of the natural vegetation in Babile Elephant Sanctuary, Ethiopia. M.Sc. Thesis, Addis Ababa University, Ethiopia.

Anteneh Belayneh, Sebsebe Demissew (2011). Diversity and population structure of woody species browsed by elephants in Babile Elephant Sanctuary, eastern Ethiopia: an implication for conservation, Agriculture and Forestry, 3(1), 20-32.

Ashenafi, Z.T., T. Coulson, C. Sillero-Zubiri and N. Leader-William (2005). Behavior and ecology of the Ethiopian wolf (Canissimensis) in a human-dominated landscape outside protected areas. Animal Conservation, 8(2), 113-12

Bal, P., Nath, C.D., Nanaya, K.M., Kushalappa, C. G and Garcia C. G. (2011). "Elephants also like coffee: Trends and drivers of human-elephant conflicts in coffee agroforestry landscapes of Kodagu, Western Ghats, India, Environmental Management, 47(5), 789-801

Berry L. (2003). Land degradation in Ethiopia: its impact and extent in Berry L, Olson J. and Campbell D(Ed): Assessing the extent, cost, and impact of land degradation at the National level: dinding and lessons learned from seven pilot case studies. Commissioned by a global mechanism with support from the World Bank

Binggli P, Desissa D (2003). Ethiopian wildlife and natural history society. Newsletter: 4-6.

Blanc, J. (2008). Loxodonta africana. The IUCN Red List of Threatened Species

Blumenbach, J. F. (1797). "2. Africanus". Handbuch der Naturgeschichte [Handbook of Natural History] (Fifth ed.). Göttingen: Johann Christian Dieterich. p. 125.

Carey C., Nigel Dudley and Sue Stolton (2000). The importance and Vulnerability of the worlds Protected Areas

Crowley, E. L. (1997). Rapid data collection using wealth ranking and other techniques. International Center for Research in agroforestry and Tropical soil Biology International Centre and Fertility Program. 16pp

Demel Teketay (1995). Floristic composition of Daketa Valley Southeast Ethiopia: An implication for the biodiversity. Mountain Research and Development, 15(2), 183-186

Desalegn Wana (2004). "Strategies for Sustainable Management of Biodiversity in the Nechsar National Park, Southern Ethiopia". A Research Report Submitted to Organization for Social Science Research in Eastern and Southern Africa (OSSREA): Addis Ababa. 
Duckworth, F.W. (2002). An assessment of Ethiopia's wildlife situation. Ethiopian Reporter, Ethiopia.

Ethiopian Wildlife and Natural History Society (EWNHS) (1996).Important Bird Areas of Ethiopia.A first inventory. Addis Ababa.300 pp.

FDRE/CSA (2013). Federal Democratic Republic of Ethiopia Central Statistical Agency

Hillman, J.C. (1993). Ethiopia: Compendium of wildlife conservation information. Ethiopian Wildlife Conservation Organization and New York Zoological Society.

Kothari, C.R. (2004). Research Methodology: Methods and techniques Second edition. New age international publishers, New Delhi, India

Mihret Ewnetu, Fedlu Abdela, Aklilu Kebede, Roman Kassahun, Hailu Mecha, Wondossen Sissay (2006). An overview of wildlife status, habitat conditions in the threats of Babile Elephant Sanctuary, and possibilities of demarcation. Ethiopian Wildlife Conservation Authority

Mohr, P.A. (1964). The geology of Ethiopia. University College of Addis Ababa Press, Ethiopia.268 pp.

Negese Nako (2014). Challenges of protecting Protected Area in Ethiopia: The Case of Maze national Park, in SNNPR in Gamo Gofa Zone.

Santiapillai, C., Wijeyamohan, S., Bandara, G., Athurupana, R., Dissanayake, N. and Read, B. (2010). "An assessment of the human-elephant conflict in Sri Lanka," Ceylon Journal of Science (Biological Sciences), 39(1), 21-33.

SDPASE/EWCA- Sustainable Development Protected Areas System of Ethiopia and Ethiopia Wildlife Conservation Authority (2015). The Economic Value and Potential of Protected Areas in Ethiopia Conservation Strategy for Africa, Volume 1 Synthesis

Sintayehu W., Anteneh B., Sena, Mohammed., Kasshaye A., Fekede R., TibebeM.and Michael Chase (2016). Elephants (Loxodonta africana) Ecology and Conservation in Babile Elephant Sanctuary

Sintayehu Workeneh D. et al. (2014). Report on Ecology and conservation of elephant in Ethiopia project report, Haramaya University, Ethiopia

Sintayehu Workeneh, Uttama Reddy R. (2014). Conflicts between the conservation of Elephant and Human activities: In the case of Babile Elephant Sanctuary (BES), Ethiopia. J. Geog. Reg. Plan, 7(1), 25-29

Sitienei GJ and Ngene SM. (2014). "Assessing the cost of living with elephants (Loxodonta africana) in areas adjacent to Meru National Park, Kenya". Europ. J. Wild. Res., 60(1), 323-330

Solomon Abebe (2014). Use and Management of Protected Areas in Ethiopia: Multiple Stakeholder Analysis of Sustainable Resource Management at Awash National Park. Requirement for the degree of Doctor of Philosophy in Environmental Science, University of South Africa (UNISA).

Solomon Chanie and Dereje Tesfaye (2015). Threats of biodiversity conservation and ecotourism activities in Nechsar National Park, Ethiopia. International Journal of Biodiversity and Conservation, 7 (3), 130-139.

Soromessa Teshome (2007). Mountain resources and conflict instigating issues, Ethiopia. Department of Biology Education, Addis Ababa University, Ethiopia.

Stephenson, J. G. (1976). Reports on the Harer Elephant dilemma. EWCO, Addis Ababa, Ethiopia. Pp $22+$ Maps.

Tahir Abdala, Yeneayehu Fenetahun (2017). Review on Floristic Diversity and Threatened Plant Species in Babile Elephant Sanctuary in East Hararge, Ethiopia, American Journal of Environmental Science and Engineering,1(1),1-6.DOI: 10.11648/j.ajese.20170101.11

United States Agency for International Development (USAID) (2008). Biodiversity Conservation and Crisis.

Vial F, Macdonald DW, Haydon DT (2011). Response of endemic afro-alpine rodents to the removal of livestock grazing pressure. Current Zoology, 57 (6): 741-750

World Bank (2011). Africa Development Indicators. Washington DC.

Yalden, D.W., M.J. Largen and D. Kock (1986). Catalog of the mammals of Ethiopia 6Perrissoddactyla, Proboscidea, Hyracoidea, Lagomorpha, Tubulidentata, Sirenia and Cetacea Monitore Zoologico Italiano (NS) Supplimento, 21(4), 31-103

Yihew Biru and Afework Bekele (2012). Food habits of African elephant (Loxodonta africana) in Babile Elephant Sanctuary, Ethiopia. International Society for Tropical Ecology,. 53(1), 43-52

Yirmed Demeke (2003). Law enforcement, illegal activity, and elephant status in Mago and Omo National Parks and adjacent areas, Ethiopia. Pachyderm, 1(1), 16-30

Yirmed Demeke (2008). The Ecology and Conservation of the relic elephant population in the Horn of Africa. Australia, Ph.D. The Thesis University of Melbourne, 1(1): 32-41

Yirmed Demeke, Marilyn, B.R, Roger, V.S. and Richard, F.B. (2006). The undisclosed facts about the relic elephant population in the Horn of Africa. Proceedings of Biological Society of Ethiopia, 16th annual conference and workshop. 13 pp.

Zelalem Wodu (2007). Elephant and anthropogenic impacts on Woody plant species in Babile Elephant Sanctuary, Eastern Ethiopia. MSc thesis, Addis Ababa University

C. Author Email: lemmageletamereba@gmail.com 